\title{
Sweden streamlines research administration
}

Declan Butler

A decade of uncertainty over who should control Swedish science could be about to end. The Swedish parliament is considering a bill to replace the country's myriad research councils with just four.

A single agency, the National Science Council, would support basic research. One applied agency would cater for social and working-life issues, another for environment and agriculture, and a fourth for industrial research.

Research has become a political hot potato in Sweden. A lack of economic growth during the early 1990s was accompanied by a $30 \%$ reduction in research spending. The centre-right coalition decided in 1994 to use US\$800 million, raised through a tax on industry, to fund a Foundation for Strategic Research. This resulted in a controversial shift towards greater support for research with socioeconomic goals.

In 1998, a parliamentary report called for a re-emphasis on basic science, and a radical streamlining of the various agencies within just four councils under the ministry of education, covering applied and basic research.

A new ally came with the return of the Social Democrats in late 1998, when 35-yearold Thomas Östros became minister for education and science. Östros has promised an increase of almost $10 \%$ in the basic research budget by 2002. Sweden's total spending on research, at $\$ 59.48$ billion or $3.6 \%$ of gross domestic product, is already high by European standards.

The new bill, endorsed by the Green and Left parties, and presented to parliament by Östros in June, adopts many of the conclusions of the 1998 report.

Being a small country, Sweden needs a single highly competitive system for distributing research funds across the universities, says Dan Brandström, chairman of the committee that will implement the new structure if the bill is passed as expected. "Before, we had a very fragmented system.”

The National Science Council will replace the current Council for Planning and Coordination of Research, the Council for Research in the Humanities and Social Sciences, the Medical Research Council, the Natural Sciences Research Council and the Research Council of Engineering Sciences. In line with the 1998 report, scientists should be in charge: most of the governing board will be elected by the research community.

Lars Nilsson heads the 54-year-old Swedish Natural Science Research Council, which will disappear under the new structure. He says that it is too soon to predict the outcome of the proposed change, but it has the "potential to be something much better".

The streamlined structure should allow

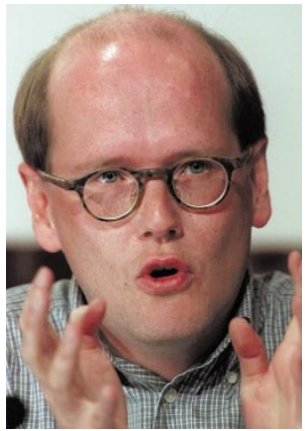

Östros: accepted plans for a single agency.

rent, professor emeritus at the University of Uppsala. "The new organization will to a large extent be run by scientists elected by the academic community," he adds, noting that the former government had politicized the research agencies.
"The cooperation between the ministry and science is more relaxed now," Nilsson agrees. He believes that the improved state of the economy has also given the present government greater room for manoeuvre.

The former research councils will survive as subunits of the council covering humanities and social sciences, medicine, and 'natural and engineering sciences'. The difficulty will be in achieving a new organizational culture, says Brandström. "The new agencies need to be more proactive. Until now they have been reactive to applications coming from funding proposals."

The agencies will be run by the ministry of education and science. But the ministry of industry will oversee the new national agency for research and development.

"It is a compromise," says Brandström. "The ministry of education and science has one main body, industry the other."

\section{Scientists back GM for Third World}

\section{David Dickson, London}

An independent panel of leading scientists from both industrialized and developing nations this week endorsed the use of genetically modified (GM) crops to meet the food needs of the world's poor.

But the panel, set up by seven national academies of science, also urged private industry to share GM technology with "responsible scientists" to alleviate hunger in developing nations.

The panel, intended to offer "scientific perspectives" on the role of GM technology in world agriculture, was set up last year by Britain's Royal Society, the national academies of the United States, Brazil, China, India and Mexico, and the Third World Academy of Sciences.

"We felt that this was a good opportunity to provide a technical reflection on the GM debate," says panel member José Fernando Perez, scientific director of the Brazilian research agency FAPESP. "In Brazil, the issue has been almost entirely discussed in political terms; we have never had a technical debate."

The report argues that, among other goals, GM technology should be used to reduce the environmental impact of agriculture. It also calls on countries to introduce systems to monitor the potential human health effects of transgenic plants.

On the question of patents, it says that unless certain plant-modification technologies are extensively licensed or provided without payment to the developing world, "they are unlikely to

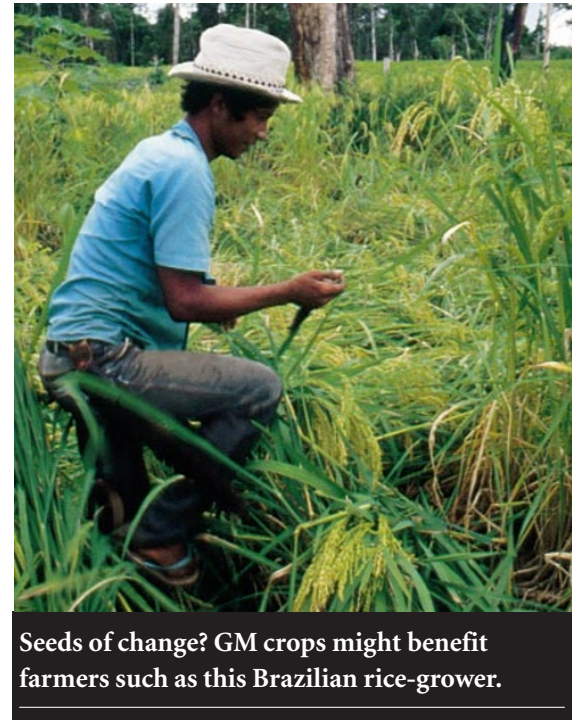

benefit the less developed nations of the world for a long time".

Critics complain that the report legitimizes high-tech solutions such as GM without giving due weight to more locally appropriate solutions. "Even if the science is sound, this cannot stand alone without questioning the power that lies behind the market approach to global hunger," says Mark Curtis, of the international development agency ActionAid.

But panel members say the report takes care to place the technical dimension of GM crops in a broader context. It demands, for example, "special exemptions" for poor farmers to protect them from "inappropriate restrictions on propagating their crops”. 